DOI 10.37882/2223-2982.2021.02-2.13

\title{
ИДЕОЛОГИЯ ТРУДОВОЙ ПОЛИТИКИ РЕСПУБЛИКИ КОРЕЯ В 1967-1987 ГГ.
}

\section{IDEOLOGY OF LABOR POLICY OF THE REPUBLIC OF KOREA IN 1967-1987}

\section{E. Ermolaeva}

Summary: 1960-1980s for the Republic of Korea were a period of rapid industrialization, which required the involvement of significant labor resources. The process of intensive economic growth in South Korea took place in an authoritarian political system. Korean government pursued a new social and labor policy with autocratic methods, including directives, coercion, and ideological leverage based on the promotion of traditional values. South Korea went through intensive social transformations, which were an integral part of economic development and contributed a lot to the growth of the education of the workforce. But at the same time that measures formed authoritarian-corporate system of labor relations, which was very convenient both for state and corporations to control people's on-work and off-work activities.

Keywords: Republic of Korea, labor policy, authoritarianism, authoritariancorporate system of labor relations, paternalism, state ideology, corporate policy, labor movement.
Ермолаева Екатерина Михайловна

К.и.н., Дальневосточный федеральный университет (Владивосток)

ermolaeva.em@dvfu.ru

Аннотация: 1960-1980-е гг. для Республики Корея стали периодом стремительной индустриализации, которая требовала привлечения значительных ресурсов, в том числе трудовых. Процесс интенсивного экономического роста в Южной Корее проходил в авторитарной политической системе, что отразилось на характере социальной политики государства. Внедрение новой трудовой политики характеризовалось автократическими методами, включавшими в себя правительственные директивы, принуждение, а также идеологические рычаги, основывающиеся на пропаганде традиционных ценностей. В Южной Корее проводились интенсивные социальные преобразования, которые являлись неотъемлемой частью экономического развития и способствовали повышению образованности рабочей силы, однако закрепили в сфере трудовых отношений наиболее удобную для контроля со стороны промышленных корпораций и государства авторитарно-корпоративную систему.

Ключевые слова: Республика Корея, трудовая политика, авторитаризм авторитарно-корпоративная система трудовых отношений, патернализм, государственная идеология, корпоративная политика, рабочее движение.

\section{Введение}

$\mathrm{H}$ ачиная с 1960-х гг. в Республике Корея (далее - РК) начала осуществляться форсированная индустриализация, инициированная военной группировкой во главе с Пак Чонхи. Развитие ориентированного на экспорт и находящегося под контролем государства экономического сектора сопровождалось автократическим стилем руководства: в стране формировался военно-бюрократический режим. Когда Пак Чонхи пришел к власти, страна оставалась преимущественно аграрной: в сельском хозяйстве, рыболовстве и лесном хозяйстве было задействовано $68,3 \%$ рабочей силы, а на производстве - только 1,5\%. Благодаря усилиям президентов РК Пак Чонхи и Чон Духвана к концу 1980-х гг. доля занятых на производстве трудовых ресурсов составила $27,7 \%$ $[4$, c. 18].

В экономике изначально упор делался на развитие легкой промышленности, конкурентоспособность которой на внешних рынках опиралась на целенаправленно поддерживаемый низкий уровень издержек производства. Зарплаты рабочих оставались невысокими, в том числе за счет низких цен на сельскохозяйственную продукцию, что в свою очередь способствовало разорению крестьян и пополнение ими рядов неквалифи- цированной рабочей силы. В 1966 г. закончилась первая пятилетка; последующие экономические планы делали акцент на развитие тяжелой промышленности, что дало толчок активной индустриализации и урбанизации. В результате доля промышленного производства превысила долю сельскохозяйственного, при этом тенденция на снижение себестоимости экспортных товаров за счет дешевизны рабочей силы сохранялась.

В 1970-е гг. государство начало прилагать активные усилия по увеличению численности рабочего класса и доли квалифицированной рабочей силы в нем. Подобная политика сопровождалась формированием авторитарно-корпоративной системы трудовых отношений, которая активно эксплуатировалась в Южной Корее и в 1980-х гг. На протяжении всех вышеуказанных периодов в РК искусственно сдерживался рост заработной платы трудящихся, при этом государство поощряло лояльных работников (предоставляя им, например, гарантии пожизненного найма или большее количество сверхурочной работы) и жестко преследовало рабочих активистов [1, с. 66-67]. Трудовое законодательство, трудовые советы и другие организации контролировали любую деятельность рабочих, внедряя идеи приоритета национального развития над личными желаниями и широко применяя патерналистскую модель взаимодействия. 
Цель нашего исследования - проанализировать процесс взаимодействия государства и рабочего класса в Республике Корея в 1967-1987 гг., раскрыть государственную стратегию по формированию лояльного государству и корпоративной политике пролетариата.

Задачи, которые способствуют достижению поставленной цели, заключаются в следующем:

- проанализировать стратегию обучения и найма рабочей силы государством;

- рассмотреть особенности взаимодействия государства и рабочих в Южной Корее в исследуемый период;

- оценить влияние традиционализма и патернализма на трудовые отношения в РК;

- рассмотреть факторы, влиявшие на самосознание и профсоюзную активность рабочих.

Хронологические рамки нашего исследования охватывают период с 1967 г. (года начала второй пятилетки 1967-1971 гг. и принятия Закона о профессиональном обучении, что форсировало рост количества квалифицированных рабочих) до конца 1980-х гг. (до начала массового движения за демократию и принятия Конституции VI Республики в 1987 г.).

\section{Индустриализашия и формирование рабочего киасса}

Ключевой проблемой процесса индустриализации в Южной Корее было отсутствие квалифицированной рабочей силы, что стало особенно актуально после выполнения первой пятилетки (1962-1966 гг.) и начала форсированного развития тяжелой и химической промышленности.

В 1967 г. правительство приняло Закон о профессиональном обучении, на основании которого было открыто большое количество профессиональных учебных заведений. Большинство из них функционировало за счет фондов зарубежных организаций, таких как Международный банк реконструкции и развития, Азиатский банк развития и Программа развития ООН, а также за счет средств Бельгии, Германии и Японии. В 1982 г. для эффективного надзора за учебными центрами и проверки технической квалификации их выпускников правительство учредило Агентство по управлению профессиональным обучением. К 1981 г. в стране функционировал 541 учебный центр; выпускниками учебных центров за период с 1967 г. по 1980 г. стали более 900000 рабочих [3, с. 355-356].

Формирование прослойки квалифицированных рабочих являлось приоритетной задачей. В 1970-х гг. Пак Чонхи пришел к выводу, что в экспортно-ориентированный экономике РК надо провести некоторые реформы, а именно, перевести экспорт с низкозатратной на продукцию с более высокой добавленной стоимостью продукцию тяжелой и химической промышленности. Результатом стал Третий пятилетний план экономического развития (1972-1976 гг.), который делал акцент на развитие тяжелых отраслей. Одновременно с этим Пак ставил задачу формирования независимой системы обороны государства, что отразилось на Пятилетнем плане по модернизации армии (1971-1976 гг.) Топовым проектом в военной сфере стала так называемая «Молниеносная операция» 1971 г. по разработке легкого вооружения [7, с. 25]. Для этого сверхсекретного проекта, который стал пилотной версией программы развития оборонной промышленности РК, стране отчаянно требовались рабочие, которые были способны проводить сверхточную обработку деталей на станках. Исследуя этот вопрос, Министерство науки и технологий сообщило, что $80 \%$ рабочей силы являются низкоквалифицированными кадрами, чье образование ограничивается средней школой, поэтому они непригодны для технически сложной работы. Главными причинами, по которым корейцы не стремились повышать квалификацию, Министерство назвало: отсутствие доступного государственного образования, низкие заработные платы по сравнению с заработком клерков, а также укоренившееся в обществе пренебрежение к рабочему классу.

В 1974 г. Пак Чонхи официально анонсировал новую образовательную политику под названием «Политика стандартизации старшей школы», которая последовала за реформой средней школы 1969 г., когда была принята система зачисления в средние классы без экзаменов [12]. Политика стандартизации должна была стимулировать детей стремиться окончить старшую школу, а также нивелировать разрыв между более престижными и рядовыми школами. Ее задачей также являлась пропаганда национального единства, общественной сплоченности и дисциплины. Экзамены при поступлении в старшие классы отменялись, так как места в эти школы распределялись через региональную лотерею, в независимости от успеваемости и личных характеристик учащегося [11, с. 584-586] . Это давало возможность ученикам пойти в школу в районе постоянного проживания, при этом был шанс попасть даже в престижное учебное заведение.

Параллельно с этим Пак Чонхи ввел субсидии на получение технического образования и некоторые другие связанные с этим льготы, стимулировал учреждение технических институтов и старших школ с техническим уклоном (техникумов), при этом ряд из них стали элитными заведениями. Техникумы делились на 4 категории: машиностроительные (введены с 1973 г. и предполагали обучение работе на станках высокой точности на машиностроительных заводах), экспериментальные (с 1976 г. - сборка оборудования, сварка, электромонтажные работы), специализированные (с 1977 г. - сборка и 
ремонт внутризаводского оборудования, в основном в сфере электротехнической, химической, сталелитейной и оборонной промышленности) и общие [7, с. 30-31]. Необходимо отметить, что на производстве была весьма сильна гендерная дискриминация: рабочими были в основном мужчины, исключение составляла электронная промышленность, а выпускницами технических школ с 1969 по 1987 гг. стало всего 9069 студенток [14, с. 69-70].

Технические навыки можно было получить на разных курсах, часть из них шла без отрыва от основной учебы или производства; на срочной службе в армии также было организовано профессиональное обучение. С 1974 г. все компании, занимающиеся ключевым производством (фабричное производство, горнодобывающая промышленность, строительство и электроника), с более чем 500 работниками обязаны были брать стажеров в количестве $15 \%$ от общего числа сотрудников. Любая компания, которая не обеспечивала обучение рабочих без отрыва от производства, подвергалась наказанию. В 1976 г. этот закон был смягчен благодаря противодействию крупных чеболей': теперь обучение стажеров обязаны были проводить компании с количеством сотрудников более 300 человек, а количество стажеров должно было быть не менее 10\% [7, с. 36].

Рабочих, задействованных на тяжелом и химическом производстве, государство наделяло особой ролью. Так, президент Пак Чонхи называл их «промышленными воинами» и «знаменосцами модернизации родины» [7, с. 20-21]. При Пак Чонхи выделялись деньги на обучение профессиональных техников, мастеров. В январе 1973 г. он провозгласил начало Национального движения за науку, которое стало официальным инструментом модернизации технологической инфраструктуры РК и повышения технического образования рабочих, особенно в секторе тяжелой и химической промышленности. Пак настоятельно рекомендовал всем «изучать и овладевать новыми технологиями», принимая участие в Движении за науку, так как «если РК хочет добиться суммы экспорта в 10 млрд долларов к 1980 г., продукты тяжелой и химической промышленности должны составлять 50\% всего экспорта» [16, с. 58-59].

Термин «промышленные воины» предполагал, что рабочие являлись солдатами, которые обеспечивали то, что Пак Чонхи называл «обороной собственными силами», которая была возможна за счет развития тяжелой промышленности, ввиду чего необходимо было массово внедрять профессиональное техническое образование. В планах по развитию тяжелой и химической промышленности были задачи по созданию целого кластера, в который входили бы частные и государственный вузы и научные институты, обсуживающиеся высокообразованными и высококвалифицированными учеными, инженерами, рабочими.

Для реализации этого амбициозного плана Пак Чонхи использовал систему военного призыва, приняв Закон об особых случаях военного призыва, по которому государство привлекало на службу образованных молодых людей (преимущественно тех, кто закончил специализированные технические вузы) для работы в приоритетных отраслях промышленности. Согласно этому закону, между солдатами, квалифицированными рабочими, инженерами, и другими группами, связанными с производством, отличий не было. Такой военизированный подход вообще был характерен для режима Пак Чонхи. Так, в 1968 г. он развернул кампанию по призыву в гражданские войска, в которые вступило 2,5 млн человек - так называемых «гвардейцев отечества» [17]. Лозунгом призыва 1968 г. был «с одной стороны строительство, с другой - оборона» [7, с. 22]. Тем самым президент требовал выполнить каждого свой двойной долг - как гражданина и солдата - перед Родиной.

Военно-промышленная лексика широко вошла в оборот: так, старший экономический секретарь О Вончхоль и его сотрудники называли себя «индустриальным корпусом», подчеркивая свой коллективный статус в национальной «индустриальной войне» и наделяя Пак Чонхи статусом своего военачальника. Такая риторика была актуальна ввиду конкуренции и противоборства с КНДР, а также раскрывала идеологический курс Пак Чонхи, основой которого стало Движение за новую деревню. Изначально Движение было направлено на улучшение сельскохозяйственного сектора, но постепенно интегрировалось в процесс индустриализации под названием «Заводское движение за новую деревню»: в новой интерпретации Пака речь уже шла не о деревне как таковой, а о «традиционном сообществе». В рамках этого движения должна была произойти духовная революция всего народа. Такие качества корейского народа, как усердие, коллективный труд, самопомощь, являясь «корнями патриотизма» и «базовыми принципами Движения за новую деревню», должны были стать основой кодекса любого работника [10, с. 209]. Каждый гражданин РК, за исключением несовершеннолетних или людей старше 65 лет обязан был посещать образовательный курсы Движения за новую деревню, а также ежемесячные «соседские собрания», которые проводились для разъяснения «современным гражданам» официальной позиции правительства и определения задач, которые оно ставило перед каждым. На всех этих мероприятиях основными фоновыми установками оставались антикоммунизм,

1 Южнокорейская форма финансово-промышленной группы, находящейся в собственности определённой семьи под единым административным и финансовым контролем. 
национализм, дисциплина и приоритет экономики.

До 1973 г. задачи индустриальной сферы подчеркнуто ассоциировали с задачами обороны и военного сектора, предлагая людям работать в режиме «военного времени». После 1973 г. к военным принципам добавили патерналистский подход: трудовые отношения стали выстраиваться по принципу семейных на основе формулы «мой совместный труд = моя семья = моя Родина» под лозунгом «наше рабочее место -- это наш дом» $[6$, с. 142]. Такие лозунги, как «мы это можем», «и это мы можем», «сила нации в экспорте» визуализировались не только на заводах, но и в министерствах, образовательных учреждениях и иных общественных институтах, включая военные [7, с. 23]. Для того чтобы сделать проект более системным, Пак объединил Национальное движение за науку и Движение за новую деревню: он мобилизовал целую «армию» профессоров, инженеров и иных экспертов, связанных с технологиями, как государственных агентов, и создал из них «группы научно-технического сопровождения Движения за новую деревню». Эти группы совместно с Корейской федерацией науки и технологий отвечали за реализацию Национального движения за науку, предпринимая ряд действий: от публикаций научно-технических руководств и аудиоматериалов, консультирования и надзора за сельской местностью до занятий с домохозяйками (стояла задача сделать из них более развитых «современных гражданок РК») [7, с. 23-24]. Университетская профессура, включая тех, кто был уволен или на пенсии, играли роль главных государственных эмиссаров, которые занимались оценкой эффективности новых заводов, консультировали различные сообщества и организации по вопросам государственной политики в сфере науки и технологий, инструктировали людей о правильной эксплуатации сельхозтехники, проводили публичные лекции по вопросам государственной политики. Задача была внедрить основы Движения за новую деревню и Национального движения за науку на самые низовые социальные уровни.

Термин «современное гражданство» предполагал, что все корейцы, активно принимая участие в Движении за новую деревню, станут «хорошими гражданами», вооруженными чувством самодостаточности (т.е. полагающимися только на себя), антикоммунистическими воззрениями, и всеми «иными аспектами, необходимыми для сохранения независимости страны» [10, с. 138]. Понятие «современное гражданство» было напрямую связано с формированием сознания «промышленного воина». Необходимо отметить, что идея «современного гражданства» была больше ориентирована на мужчин. Государство вербовало молодых людей - способных юношей, часто из бедных сельских или рыбацких районов, предлагая им финансовую поддержку и льготы при обучении в учебных заведениях технического профиля. После окончания обучения они становились «специаль- ными солдатами» в рамках Движения за новую деревню и отдавали свой долг Родине, а работа женщин обосновывалась патерналистской семейной культурой - они выполняли свои традиционные вспомогательные обязанности, как дома, так и на рабочем месте.

Вся совокупность мер, предпринимаемых властями, привела к весьма эффективному результату в увеличении рабочего класса и формировании слоя квалифицированной рабочей силы, особенно в сфере тяжелой и химической промышленности. Успех был достигнут за счет целенаправленности и централизованности государственной политики. Молодые люди спешили воспользоваться всеми субсидиями, которые им предлагали. Заключая двусторонний контракт с государством, гражданин РК имел возможность пройти хороший профессиональный трейнинг в технических областях и воспользоваться результатом как для собственной выгоды, найдя работу за рубежом (пример - Ближний Восток [2]), так и для модернизации своей родины. Эти замотивированные люди стали «знаменосцами модернизации Родины» - квалифицированной рабочей силой, сотворившей экономическое чудо (так называемое «чудо на реке Ханган») 1970-1980-х гг. Другой стороной медали стал тот факт, что рабочие, которые в 1970-х гг. получали образование и трудовой опыт под эгидой и жестким контролем государства, в 1980-х гг. были максимально включены в рабочее движение, будучи недовольными социальной политикой Чон Духвана и став ударной силой демократизации страны [7, с. 40].

\section{Авторитарно-корпоративная система трудовых отношений}

Патернализм в трудовых отношениях стал основой авторитарно-корпоративной системы управления на производстве. Такой тип взаимодействия неплохо приживался в корейских рабочих коллективах, так как в основе лежали классические конфуцианские ценности. Конфуцианские нормы диктовали, что общественная иерархия, построенная и жестко регламентированная по принципу старшинства, формировала общественную гармонию и обеспечивала стабильное существование государства. Правительство и топ-менеджеры на производствах использовали традиционную логику выстраивания социальной иерархии для того, чтобы сформировать лояльных государству и крупному капиталу работников, которых призывали относиться к работодателям как к своим родителям. Управляющие кадры не только руководили производством, а, исходя из вышеуказанной схемы, подчиняясь напрямую государству, являлись проводником его воли. Управленческие решения предприятий всегда согласовывались с официальной государственной политикой, более того, корпорации также должны были доказывать свою лояльность государству и делать необходимые вклады в развитие 
национальной экономики. Все производственные единицы относились к так называемому «национальному индустриальному корпусу», члены которого - рабочие, в том числе - должны были ставить в приоритет не столько корпоративные, сколько общегосударственные интересы, полностью отринув личные. К последним относились требования повышения зарплат и улучшений условий труда, предоставление социальных гарантий. Модель организации труда на предприятиях заимствовала во многом военные черты. Руководители многих предприятий вводили на производствах форму (часто серого цвета), заставляли своих сотрудников коротко стричься. Статус работника определялся особой формой именных бейджей, которые прикреплялись к нагрудному карману. Кроме того, активно использовалась армейская лексика, такая как «солдат производства», «линия производственного фронта», «строительство и война», «экспортная война», «взять экспортную высоту в 10 млрд долл.» [3, с. 361-362]. Один из руководителей профсоюза Хёндэ Индастри в городе Ульсан в своем интервью рассказывал, о том, что рабочие трудились «как собаки» и обращались с ними «как с животными» или «заключенными», штрафуя даже за длину волос [7, с. 45].

Конфуцианские ценности были глубоко интегрированы в структуру южнокорейских компаний. В первую очередь - это взаимодействие внутри рабочих коллективов, ориентированное на семью и семейные ценности: все члены позиционировались как одна семья, что оказывало влияние на достижения работников, выбор деятельности и характер отношений на производстве. При этом процесс принятия управленческих решений в компаниях был очень централизован: высшее руководство не передавало свои полномочия подчиненным и несло личную ответственность за все основные процессы на предприятии. Такая позиция тоже связана с традиционным пониманием старшинства: старший - значит, более мудрый. Ввиду культа старшинства и возраста как такового, младшие, но более талантливые не имели возможности стремительного карьерного роста. Существовал строгий порядок, где каждый «член семьи» имел свой собственный статус: «сын» не мог быть выше «отца» и т.п. Необходимо отметить, что родственный статус влиял на южнокорейские компании не только в идеологическом, но и прямом смысле: высший руководящий состав промышленных корпораций чаще всего был представлен близкими родственниками, а сама компания передавалась по наследству. Вышеуказанная схема гармонично встраивалась в корейскую социальную систему не только в период индустриализации, но и в последующие периоды: родственные связи и наследственные алгоритмы сохраняются в южнокорейских компаниях до сих пор, а сотрудники южнокорейских предприятий и в нынешнее время наделяют руководство абсолютной властью, прощая им часто автократические методы управления.
Подобная система зиждется на главном принципе достижения единства и гармонии, который, с отсылкой к «мудрости древних», заключается в правильной социальной иерархии, почитании старших и признании их авторитета [8, с. 36-37].

Рабочие коллективы являлись достаточно замкнутыми сообществами, что очевидно даже из самого процесса найма. Информацию о наличии свободных мест на предприятиях большинство рабочих получали от своих знакомых и родственников, хотя объявления печатались в СМИ или на стендах в публичных местах. Очевидным «патерналистским штрихом» при трудоустройстве являлась необходимость найти поручителей среди уже работавших на производстве людей, которые могли подтвердить личность и материальное положение новичка. Поручители соглашались компенсировать любой ущерб, который мог нанести имуществу завода вновь прибывший [3, с. 356]. Такая система найма была эффективна и удобна для работодателей. Во-первых, получение сведений о найме через знакомых и родственников делало эту информацию более эксклюзивной, и повышало престижность самой работы на предприятии. Одновременно с этим возможность уже работающего человека привести на завод нового, автоматически повышало и его статус. Во-вторых, такая система найма заставляла сотрудников ощущать себя ближе друг к другу: постоянно ручаясь за товарищей по работе, они чувствовали себя «в одной лодке».

Система оплаты труда тоже являлась частью государственной и корпоративной политики, отражающей специфику индустриального процесса. Задача предприятий была вполне очевидна: удовлетворить свой спрос на квалифицированную в нужной им степени рабочую силу, при этом сдерживать зарплаты на определенном уровне. Работодатели создали весьма гибкую систему оплаты, которая заключалась в премировании и компенсации сверхурочных часов исходя из субъективной оценки руководителями индивидуальных достижений рабочих. При этом не было конкретной шкалы или простого понимания, какие аспекты являются приоритетными, а потому оплачиваются более высоко. В списке таковых были: продуктивность, опыт, уровень квалификации, образование, трудовой стаж или иные показатели, в том числе семейный статус (часто премии или дополнительное количество сверхурочных часов давали за факт вступления в брак или рождение детей) [3, с. 359-363].

Работодатели ставили цель предотвратить профсоюзное движение и любые протесты, а также стремились остановить текучку кадров, которые в поисках более высокой заработной платы переходили с предприятия на предприятие. Система оплаты труда через распределение сверхурочных часов работы позволяла поощрить человека за какие-либо личные качества или достиже- 
ния, однако, фактически, человеку всего лишь позволяли работать больше. Поощрялись те работники, кто в независимости от своих профессиональных качеств, проявлял большую лояльность, энтузиазм и те, кто следовал формальным предписаниям менеджеров. Эта система приводила к тому, что квалифицированный и низкоквалифицированный труд могли оплачиваться одинаково. Официальное объяснение такой бессистемной и «творческой» оплаты труда было весьма логичным: по словам руководства компаний, всем предоставлялись равные возможности, что позволяло не сталкивать разные группы рабочих между собой [3, с. 359-363].

Инструментами предотвращения рабочего протеста на предприятии являлись не только корпоративная идеология и система оплаты труда. Власти выступали категорически против профсоюзного движения. Государство оценивало деятельность рабочих союзов как «конфликтных, непродуктивных и разрушительных для экономики» и приступило в конце 1960-х гг. к формированию специальных советов, которые должны были осуществлять функции профсоюзов [3, с. 361]. Эти советы получили легальный статус после принятия в 1980 г. Закона о трудовых советах, согласно которому все предприятия, на которых трудится более 100 человек, должны были формировать советы, состоящие в равной степени из рабочих и управленцев [15]. Задачами каждого совета было повышение продуктивности производства, обучение рабочих, разрешение трудовых споров, защита интересов членов трудового коллектива, улучшение рабочей среды и укрепление сотрудничества рабочих и управленческих кадров [3, с. 359-363]. Идеологической базой этих советов стало Фабричное движение за новую деревню, а слоганом: «Обращайся с трудящимися как с семьей... Трудись на заводе как на своем собственном» $[10$, с. 210]. Кроме того, под эгидой Пак Чонхи была создана Федерация профсоюзов Кореи, которая формально защищала права рабочих, но подчинялась интересам государства и крупных корпораций.

В 1980-х гг., после прихода к власти Чон Духвана, в отношении профсоюзов были приняты законы, которое исследователи называют «беспрецедентно репрессивными» или «драконовскими». Согласно этим законам, структура профсоюзов менялась с отраслевой на корпоративную, а процедура их формирования стала весьма сложной. В дополнение к этому, ряд государственных органов получили полномочия распустить профсоюз по своему усмотрению [7, с. 48]. Кроме того, новое рабочее законодательство запрещало участие «третьей стороны» в профсоюзной деятельности. Эта мера была необходима для того, чтобы предотвратить вмешательство в рабочее движение радикальных студенческих лидеров и представителей христианской церкви, которые направляли, организовывали, политизировали деятельность рабочих, а также провоцировали их на массовые акции. Устранение рабочих активистов проходило и физически: сотни профсоюзных лидеров были арестованы или отправлены в «лагеря очищения» на принудительные работы.

Всплески рабочего движения в Южной Корее происходили регулярно, начиная с периода образования Республики Корея, однако они стали по-настоящему массовыми, организованными и идеологически выверенными только к концу 1980-х гг. Не последнюю роль в этом процессе сыграла политика государства, направленная на профессиональное образование рабочих и формирование у них сознания «современного гражданина». Вместе с тем коллективное поведение южнокорейский рабочих в 1970-1980-е гг. не отличалось однородностью и постоянством, а их консерватизм или радикализм во взаимодействии с работодателями и властями зависел от ряда факторов. К этим факторам можно отнести территориальный и отраслевой: в ряде городов и на ряде производств рабочее движение было активнее, чем в среднем по стране. Территориальный принцип напрямую связан с урбанизацией, так как промышленные предприятия являлись стимулом роста городов. Если говорить о 1970-х и 1980-х гг. в Южной Корее, то более интенсивно инфраструктура менялась в столичном регионе и юго-восточной части страны, где количество рабочих объективно было выше. Фактически, в период интенсивной индустриализации, направленной на экспорт, промышленные зоны создавались только в двух провинциях - Кёнги и Кёнсан (Северный и Южный), при этом предприятия легкой промышленности преимущественно переносились в столичный регион, а тяжелая промышленность концентрировалась на юго-востоке [5, с. 450-451)].

Если говорить об отраслевом факторе, то он играл незначительную роль, однако здесь мы в качестве примера можем отметить более высокий консерватизм и меньшую активность рабочего движения в сфере судостроения. Так, в городе Ульсан, где находится судостроительная верфь корпорации Хёндэ, до 1987 г. практически не было никаких серьезных вспышек рабочего движения кроме забастовки в 1974 г. Хёндэ проводила максимально жесткую кадровую политику, следуя общегосударственным задачам и собственной выгоде, при этом у рабочих, задействованных на ее производстве, наблюдались наиболее длительные контракты (в среднем 8,4 года), что говорит об их лояльности, а также самом низком уровне образования (у многих оно оставалось на уровне начальных классов). [7, с. 45] В судостроении поощрялась физическая сила, поэтому корпорация Хёндэ не требовала даже сертификата об окончании средней школы. В итоге наименее грамотные представители рабочего класса позже остальных включились в борьбу за свои права и движение за демократию в целом. 
Тяжелая промышленность находилась в фокусе государства, которое направило все усилия на развитие ее отраслей и давало возможность корпорациям предпринимать самые жесткие меры в отношении рабочих, а также осуществлять за ними тотальный, в том числе идеологический, контроль. Тем не менее, рабочие большинства отраслей тяжелой промышленности, будучи относительно более образованными и являясь объектами влияния со стороны студенческих и христианских организаций, продемонстрировали наиболее высокий уровень политической активности. Особенно это было справедливо для юго-восточного региона страны, где росли так называемые «новые индустриальные города», такие как Масан и Чангвон, в которых рост населения, а, значит, и рабочих, проходил весьма стремительно. Так, в Чангвоне с 1980 по 1986 г. кол-во рабочих увеличилось на $61 \%[9$, с. 160$]$.

Новые промышленные города отличались тем, что было названо феноменом «слепого формирования жилищных сообществ рабочих» [14, с. 81-93], которые складывались внутри какой-то определённой промышленной корпорации, за счет перемещения рабочих в одну местность со всей страны. Переселяясь на новое место жительства, с семьей или без, изначально они размещались в общежитиях, которые предоставлялись работодателями, а затем арендовали жилплощадь в многоквартирных домах, которые также были заполнены в основном семьями рабочих. Таким образом, коммуникация рабочих происходила постоянно, не ограничиваясь рабочим местом. Их взаимодействие преодолевало региональный фактор (фактически они съезжались со всех уголков страны) и концентрировалось на трудовой сфере. Формировалось сообщество, характеризующееся типичными для Кореи устойчивыми социальными связями, трудовой солидарностью, коллективным сознанием и особой культурой. Так, г. Ульсан известен «сообществом свободы», которое включало рабочих компании Хёндэ, проживающих в нескольких жилищных комплексах и которые сообща выступили против диктатуры в период рабочего движения конца 1980-х гг. [7, с. 43ᄀ-44]. Такие сообщества имели достаточно замкнутую структуру, но благодаря постоянному общению их членов, а также специфике корпоративной политики, являлись весьма сплочённым звеном, которое было способно оказывать влияние на локальный социально-экономический процесс.

\section{Зак^ючение}

Лозунг «экономика - прежде всего» и интенсивная индустриализация в Южной Корее в 1970-1980-х гг. подчинили своим целям социальную сферу и оказали огромное влияние на трудовую политику государства. Правительство ставило конкретные задачи перед обществом, выполнять которые должны были все ресурсные единицы, к которым оно причисляло как каждого гражданина в отдельности, так и различные социальные институты. Ставка делалась на крупнейшие компании, которые являлись основными проводниками государственной экономической политики и политики в отношении трудовых ресурсов РК.

Поставив задачу по увеличению квалифицированной рабочей силы в приоритетных отраслях промышленности в 1970-1980-х гг., государство построило несколько алгоритмов взаимодействия с пролетариатом: напрямую и опосредованно. Опосредованный алгоритм предполагал посредническую функцию чеболей, коим давали некоторую свободу действий в отношении своих трудовых ресурсов, но в рамках поставленных национальных задач. Напрямую государство обращалось к гражданам РК, предлагая им обучающие курсы по «повышению национального самосознания», а также субсидии на получение технического образования по специальностям, которые требовались на производствах. Молодежь активно рекрутировали на производство, сочетая этот процесс с идеологической обработкой в духе национализма, антикоммунизма и экономических приоритетов. Подобные процессы происходили и внутри чеболей, где на производстве соблюдалась строгая дисциплина, сохранялась ориентация на продуктивность, а также практиковался традиционализм и патернализм в выстраивании системы социальных связей внутри рабочих коллективов.

Государство и крупный капитал не были заинтересованы в активизации рабочего движения, ввиду чего использовали весь спектр рычагов для уменьшения мобильности рабочих, а также поддержания их лояльности и энтузиазма. Отклик рабочего класса не был однозначным: растущий уровень социально-политической грамотности позволял профсоюзному движению набирать обороты, несмотря на репрессивное трудовое законодательство 1970-х и «драконовское» 1980-х гг. Тем не менее, на достаточно длительный период государство смогло мобилизовать трудовые ресурсы, сдерживая общество от взрыва и используя людские ресурсы для впечатляющего экономического роста. И не смотря на начало демократического транзита в конце 1980-х - начале 1990-х гг., основные идеологические установки, использовавшиеся в авторитарно-корпоративной системе труда и направленные на сплочение трудовых коллективов через пропаганду государственных задач и семейных ценностей, сохранились и получили дальнейшее развитие. 


\section{ЛИТЕРАТУРА}

1. Иванов, Д.В. По следам «тигра»: анализ траекторий социальных изменений в Южной Корее / Д.В. Иванов // Региональные исследования. - 2012. №4. - C. 63-89.

2. Ким, Г.Н. Корейские контрактники на Ближнем Востоке / Г. Н. Ким. [Электр. ресурс]. - URL: http://world.lib.ru/k/kim_german_nikolaewich/27.shtml

3. Bae, Kyuhan. Labor Strategy for Industrialization in South Korea / Bae Kyuhan // Pacific Affairs. - 1989. - Vol. 62, № 3. - P. 353-363.

4. Chaudhuri, S. Government and Economic Development in South Korea, 1961-79/ S. Chaudhuri // Social Scientist. - 1996. - Vol. 24, № 11/12. - P. 18-35.

5. Hashiya, H. Urbanization in the Republic of Korea and Taiwan: a NIEs pattern // The Developing Economies. - 1996. - XXXIV-4. - P. 447-469.

6. Kim, Hyung-A. Korea's development under Park Chung Hee / Kim Hyung-A. - London: Routledge Curzon, 2004. - 280 p.

7. Kim, Hyung-A. Korean Skilled Workers, Toward a Labor Aristocracy / Kim Hyung-A. - Washington: University of Washington Press, 2020. - 232 p.

8. Lee, Choong Y. South Korean Corporate Culture and Its Lessons for Building Corporate Culture in China / Choong Y. Lee, Jennifer Y. Lee // The Journal of International Management Studies. - 2014. - Vol. 9, №2. - P. 33-42.

9. Markusen, A. The State as Industrial Locator and District Builder: The Case of Changwon, South Korea / A. Markusen, Sam Ock Park // Economic Geography. Defense Spending and Regional Development. - 1993. - Vol. 69, № 2. - P. 157-181.

10. Park, Chung Hee. Saemaul: Korea's New Community Movement / Park Chung Hee. - Seoul: Korea Textbook Company, 1979. - 266 p.

11. Park, Sang-Young. Crafting and dismantling the egalitarian social contract: the changing state-society relations in globalizing Korea / Park, Sang-Young // The Pacific Review. - 2010. - Vol. 23, 5 issue. - P. 579-601.

12. 고교평준화 정책의 반성 // 강원 일보. - [Электр. ресурс]. - URL: http://www.kwnews.co.kr/nview.asp?s=1101\&aid=206111600023 Последствия политики стандартизации в старших классах // Канвон Ильбо.

13. 김준. 잃어버린 공동체? 울산 동구지역 노동자 주거공동체의 형성과 해체// 경제와 사회. - 2005. - №68. -71-106쪽. Kum Чун. Потерянное сообщество? Формирование и распад жилищного сообщества рабочих в Донгу, г. Ульсан // Экономика и общество.

14. 김춘수. 1960-70년대 국가의 여성 배제 전략 - 기술교육훈련을 중심으로역사학연구소 // 역사연구. - 2003. - 제12호. 69-107쪽. Национальная стратегия исключения женщин в 1960-1970-е гг.: на примере технического образования // Исторические исследования.

15. 노사협의회법. 1980. 12.31. 제3348호. [Электр. ресурс]. - URL: https://www.law.go.kr/LSW/lsInfoP.do?lsiSeq=156\#0000 Закон 0 трудовых советах. №3348 от 31 декабря 1980 г.

16. 박정희 대통령 연설문집 제7집. - 서울: 대통령비서, 1973. - 544쪽. Сборник речей президента Пак Чонхи. - Сеул: Секретариат президента, 1973. -544 c.

17. 향토예비군설치법시행령. 대통령령제3386호, 1968. Закон о создании национальной гвардии. № 3386 от 27.02.1968. - [Электр. ресурс] URL: http://www.law.go.kr/법령/향토예비군설치법시행령 /(03386,19680227)

( Ермолаева Екатерина Михайловна (ermolaeva.em@dvfu.ru). 